\title{
The Causal Priority of Form in Aristotle
}

\author{
Kathrin Koslicki \\ Department of Philosophy, University of Alberta
}

In various texts (e.g., Met. Z.17), Aristotle assigns priority to form, in its role as a principle and cause, over matter and the matter-form compound. Given the central role played by this claim in Aristotle's search for primary substance in the Metaphysics, it is important to understand what motivates him in locating the primary causal responsibility for a thing's being what it is with the form, rather than the matter. According to Met. $\Theta .8$, actuality [energeia/entelecheia] in general is prior to potentiality [dunamis] in three ways, viz., in definition, time and substance. I propose an explicitly causal reading of this general priority claim, as it pertains to the matter-form relationship. The priority of form over matter in definition, time and substance, in my view, is best explained by appeal to the role of form as the formal, efficient and final cause of the matter-form compound, respectively, while the posteriority of matter to form according to all three notions of priority is most plausibly accounted for by the fact that the causal contribution of matter is limited to its role as material cause. When approached from this angle, the work of Met. $\Theta .8$ can be seen to lend direct support to the more specific and explicitly causal priority claim we encounter in Met. Z.17, viz., that form is prior to matter in its role as the principle and primary cause of a matter-form compound's being what it is.

Keywords: matter, form, cause, principle, priority, substance

\section{Introduction}

In various texts, Aristotle assigns priority to form, in its role as a principle and cause, over matter and the matter-form compound. ${ }^{1}$ This alleged causal

Corresponding author's address: Kathrin Koslicki, Department of Philosophy, University of Alberta, 2-40 Assiniboia Hall, Edmonton, Alberta T6G 2E7, Canada. Email: kathrin.koslicki@ualberta.ca.

1 At Phys. II.1, 193b6-12, for example, Aristotle states that the form of a natural matter-form compound is more properly considered its nature than the matter. A nature, in this context, is characterized as an internal principle of change and stability within a natural matterform compound which accounts for the various kinds of changes matter-form compounds can undergo: substantial change (viz., coming to be or ceasing to be), qualitative change (viz., alteration), quantitative change (viz., growth and decrease) and change with respect 
priority of form plays an important role in the conception of substance Aris-

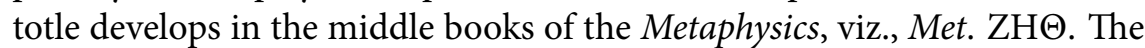
fact that form, in Aristotle's view, is causally prior, to matter and the compound weighs heavily in favor of his assessment that form comes out as the primary contender for the role of substance, more so than matter and the compound:

Therefore what we seek is the cause, i.e. the form, by reason of which the matter is some definite thing; and this is the substance of the thing. (Met. Z.17, 1041b7-9) ${ }^{2}$

And this [the form] is the substance of each thing; for this is the primary cause of its being; and since, while some things are not substances, as many as are substances are formed naturally and by nature, their substance would seem to be this nature, which is not an element but a principle. An element is that into which a thing is divided and which is present in it as matter, e.g. $a$ and $b$ are the elements of the syllable. (Met. Z.17, 1041b27-33)

But the matter and the compound, as Aristotle tells us in other texts, also function as causes and principles in various respects. ${ }^{3}$ The question thus arises as to why form should be regarded as prior to matter or the compound in its role as a principle and cause? Given the centrality of this claim for Aristotle's conception of substance in the Metaphysics, it is important to understand what motivates him in locating the primary causal responsibility for a thing's being what it is with its form.

My main focus in this paper is on the question of why Aristotle designates the form of a matter-form compound, rather than the matter, as the primary principle and cause of the compound's being what it is. But this larger question can be further clarified by distinguishing the following two

to place (viz., locomotion). My starting-point, in this paper, will be Aristotle's remarks in Met. Z.17 concerning the priority of form over matter in its role as a principle and cause.

2 This and all subsequent passages from the Metaphysics come from the translation by W. D. Ross (see Barnes 1984).

3 For example, in the context of Aristotle's analysis of change in Phys. I, both the matter and the matter-form compound are characterized as principles in their role as subjects of change: the matter is that which underlies substantial change; and the matter-form compound is that which underlies qualitative, quantitative and locomotive change. Moreover, even though the form of a matter-form compound, according to Phys. II.1, 193b6-12, is said to be its nature more so than the matter, the matter is nevertheless also designated as $a$ nature of the matter-form compound in Phys. II.1, i.e., as an internal principle of change and stability, and as the material cause in Phys. II.3. In addition to their role in Aristotle's analysis of change, both the matter and the matter-form compound are also said to function as subjects of predication (e.g., Met. Z.3). For a classic discussion of Aristotle's four causes, in relation to Plato's forms-as-causes doctrine, see (Fine 1987). 
more specific sub-questions. The first asks what sorts of causal roles Aristotle ascribes to form, as compared to matter, such that form at the end of the day, in Aristotle's ranking, comes out as causally prior to matter. The second presupposes a certain answer to the first more specific sub-question and then proceeds to ask why, in Aristotle's view, it is the form, rather than the matter, which occupies the causal roles in question. I take myself, in this paper, to be addressing both of these more specific sub-questions. Aristotle's position in Met. Z.17 is that form is the primary cause and principle of a matter-form compound's being what it is. To my mind, both the content of this claim and Aristotle's motivation for holding it must be unpacked further in order to arrive at a satisfactory understanding of the position Aristotle advances in Met. Z.17, as well as in his investigation into substance in Metaphysics $\mathrm{ZH \Theta}$ as a whole. Thus, in what follows, I attempt to shed light both on the question of what sorts of causal roles Aristotle ascribes to form, when he declares form to be the primary cause and principle of a matterform compound's being what it is; and on the question of why it is the form of a matter-form compound, rather than its matter, which accomplishes this causal work, in Aristotle's view.

\subsection{The Posteriority of the Matter-Form Compound ${ }^{4}$}

Although this interpretation is no doubt controversial, I read Aristotle as having already disqualified matter-form compounds from primary substance status by the time he arrives at his more considered views concerning substance in Metaphysics $\mathrm{ZH \Theta}$. At this point in his investigation, the real competitors are now matter and form, viz., the principles and causes of matter-form compounds. This development is of course surprising especially when evaluated against the background of the Categories, where, as is well-known, Aristotle classifies concrete particular objects (e.g., individual living organisms) as primary substances. The Categories, however, is generally taken to be one of the earliest, if not the earliest, of Aristotle's written works. When we turn to such texts as the Physics, De Anima and the Metaphysics, in contrast, we notice that Aristotle's views have undergone a definitive shift and he now regards his previous ontological frontrunners as further analyzable into explanatorily more basic constituents, viz., their matter and their form. Although we still find Aristotle referring to concrete particular objects as substances (ousiai), even once his hylomorphic analysis is on the table, these entities have apparently forfeited their status as primary substances and are now classified as posterior or secondary, due to their particular brand of metaphysical complexity. Aristotle expresses this sentiment,

4 The issues treated in this section are discussed in greater detail in (Koslicki 2014). 
for example, in the following remark from Met. Z.3:

The substance compounded of both, i.e. of matter and shape, may be dismissed; for it is posterior and its nature is obvious. (Met. Z.3, 1029a30-32)

While matter-form compounds figure saliently in our common-sense experience of the world, they constitute for Aristotle merely the startingpoint, but by no means the end-point, of metaphysical inquiry:

It is agreed that there are some substances among sensible things, so that we must look first among these. For it is in an advantage to advance to that which is more intelligible. For learning proceeds for all in this way-through that which is less intelligible by nature to that which is more intelligible; and just as in conduct our work is to start from what is good for each and make what is good in itself good for each, so it is our work to start from what is more intelligible to oneself and make what is intelligible by nature intelligible to oneself. (Met. Z.3, 1029a33-4, 1029b3-12) ${ }^{5}$

Once these experientially salient objects have been subjected to further metaphysical analysis, the explanatorily more basic constituents into which they have been "dissolved", viz., their matter and form, are now in a better position to qualify for the title, "substance", than the concrete particular objects themselves of which they are the principles and causes.

When Aristotle continues to refer to matter-form compounds as substances, even while in the same breath designating them as explanatorily posterior or secondary, I take him to be employing his term, "ousia", in a primarily taxonomic way, i.e., to single out certain kinds of being, without

5 The manuscripts place the passage starting with "For it is an advantage to advance..." and ending with "... and make what is intelligible by nature intelligible to oneself" (1029b31029b12) at the beginning of Aristotle's discussion of essence in Met. Z.4, rather than at the end of his remarks concerning subjecthood in Met. Z.3. Commentators, however, tend to view the passage as misplaced there, since it lacks continuity with the first few lines of Met. Z.4 (1029b1-3), and find that it makes better sense when inserted, as above, between Met. Z.3, 1029a34, and Met. Z.4, 1029b1-3. We cannot very well assume that Aristotle would characterize essence as an easily accessible starting-point for human inquirers who are engaged in an investigation concerning substance. In addition, we are told at 1029a32-33 that form, which is in the subsequent chapters identified with essence, is difficult to understand and must be investigated further. Thus, the canned remark characterizing learning as a progression from "what is more intelligible to us" to "what is more intelligible by nature", which we find elsewhere as well, is most straightforwardly interpreted here as referring to sensible substances, i.e., matter-form compounds. Aristotle's statement at 1029a32 that "matter is also in a sense manifest (phanera)", however, remains puzzling. For further discussion concerning the placement and interpretation of this passage, see for example (Bostock 1994, 80-85), (Burnyeat 1979, 16), (Burnyeat 2001, 16-18), (Frede and Patzig 1988, 49-56), and (Ross 1924, 166). 
thereby simultaneously committing himself to the idea that these entities must be assigned the most privileged ontological position within his ontology. Given this taxonomic use of the notion of substance, matter-form compounds are labeled by Aristotle as substances simpliciter, using the notion of substance in an absolute, i.e., non-relational and non-comparative, way. In contrast, when Aristotle designates the form of a matter-form compound as the primary contender for the role of substance more so than the matter, as he does in Met. Z.17, I read him as employing the notion of substance there in both a relational and a comparative way: in a relational way, since he regards the form of a matter-form compound as the substance of the matter-form compound; and in a comparative way, since form, in Aristotle's view, qualifies for the title, "substance", more so than matter does. ${ }^{6}$ On my reading, Aristotle puts to use his notion of substance in these latter two ways (i.e., relationally and comparatively) not merely taxonomically, to single out certain kinds of being (viz., matter and form); rather, he is also indicating a certain non-taxonomic priority ranking, according to which matter and form, as the principles and causes of matter-form compounds, occupy explanatorily a more privileged position within his ontology than the matter-form compounds with which they are associated.

For these reasons (as indicated here only very briefly), I take it that matter-form compounds, at this point in Aristotle's investigation into substance in Metaphysics $\mathrm{ZH \Theta}$, are no longer considered to be the main contenders for the title, "primary substance". The new frontrunners are now their principles and causes, viz., matter and form, the substances of matterform compounds. The really pressing question on Aristotle's mind in Met. Z.17, which has occupied him throughout Met. Z, is whether and why it is the form of a matter-form compound that is more deserving of primary substance status than the matter, according to a comparative, relational and non-taxonomic use of the notion of substance.

\subsection{Met. Z.17: Form as Principle and Primary Cause of Being}

In Met. Z.17, the final chapter of Met. Z, Aristotle sets out on a fresh start, one of several such new beginnings we encounter along the way in Met. Z.

${ }^{6}$ As I argue in (Koslicki 2014), it is not at all obvious that we should read Aristotle as also wanting to take the further step and classify form as substance simpliciter (according to a non-taxonomic and absolute use of the notion of substance). This strategy appears runs afoul of a principle Aristotle endorses in Met. Z.13, according to which no substance can have other substances present in it actually (see 1039a2-14). At the end of the day, then, we may end up with an ontology in which there are no primary substances simpliciter in the non-taxonomic sense, since the most privileged position within this ontology is occupied by a type of entity, viz., form, which qualifies for primary substance status nontaxonomically only in a relational, and not in an absolute, sense. 
The question he is pursuing in this chapter, as well as elsewhere in Met. Z, is "What and what sort of thing is substance?". His strategy here is to attempt to answer this question by following the lead, "substance is a principle (archē) and a cause (aitia)":

We should say what, and what sort of thing, substance is, taking another starting-point; [...]. Since, then, substance is a principle (archē) and a cause (aitia), let us attack it from this standpoint. (1041a6-10)

A cause, Aristotle tells us, is what is stated in response to certain kinds of "why"-questions. The particular "why"-questions which are of primary interest to Aristotle in Met. Z.17 appear to be, at least initially, of the form: "Why is a certain kind of thing the kind of thing that it is?" or "Why is something the kind of thing that it is?", e.g., "Why is a house a house?" or "Why is something that is a house a house?". Rephrasing these questions in a somewhat different way, we might put the main issue with which Aristotle is concerned in this chapter as follows: "What makes something the kind of thing that it is (e.g., a house)?" or "In virtue of what is a thing the kind of thing that it is (e.g., a house)?". I interpret these questions as asking whether a thing's membership in the kind to which it essentially belongs can be further explained in terms of anything else about the thing in question. ${ }^{7}$ The correct answer to these questions, in Aristotle's mind, is one which states the cause of a thing's being what it is (e.g., a house, a human being, a syllable, or flesh); and this, so Aristotle argues in this chapter, is the essence of the thing: ${ }^{8}$

Plainly we are seeking the cause (to aition). And this is the essence (to ti èn einai) (to speak abstractly (logikōs)), which in some cases is that for the sake of which, e.g. perhaps in the case of a house or a bed, and in some cases is the first mover; for this also is a cause. But while the efficient cause is sought in the case of genesis and destruction, the final cause is sought in the case of being also. (Met. Z.17, 1041a27-32)

7 Here, it is important to keep in mind that Aristotle often finds it easier to illustrate what he wants to say about natural things, in particular living organisms, by means of examples involving artifacts (e.g., houses or syllables). Somewhat frustratingly, Aristotle engages in this practice even when he does not believe that the claims in question really, at the end of the day, apply to artifacts. We are told at Met. Z.17, 1041b28-30, that "while some things are not substances, as many as are substances are formed naturally and by nature"; and, at Met. Z.16, 1040b5-16, that even the parts of living organisms as well as the so-called simple bodies or elements (e.g., earth, air, water and fire) are now excluded from substance status, despite their appearance on the initial list of reputable substance candidates given in Met. Z.2. The disanalogies between artifacts and living organisms in Aristotle are discussed further in (Koslicki 1997).

${ }^{8}$ Why the cause and not $a$ cause? After all, following Aristotle's famous doctrine of the four causes, we might expect that there is more than one acceptable answer to the "why"questions at issue. We will have occasion to take up this issue in more detail below. 
Aristotle's discussion in Met. Z.17 suggests that he intends the model he has set out for scientific inquiry in the Posterior Analytics to carry over to the present metaphysical examination. ${ }^{9}$ According to the approach to scientific theorizing Aristotle develops in the Posterior Analytics, a scientist is in a position to produce the correct answer to a scientific "why"-question, such as "Why (in general) does thunder occur?", once she has grasped the essence of the phenomenon under consideration, i.e., once she knows what the correct answer is to questions of the form, "What is thunder?" or "What is it to be thunder?". Both types of questions, in Aristotle's view, are correctly answered by stating the cause, represented by the so-called "middle term" in the accompanying demonstrative syllogism. Thus, the question, "Why (in general) does thunder occur?", receives the answer, "Because fire is extinguished in the clouds", which in this case states the efficient cause of the phenomenon under consideration (fire being extinguished in the clouds). The question, "What is (it to be) thunder?", is answered by giving the full definition, or statement of the essence, of thunder, viz., "Thunder is a kind of noise in the clouds caused by the extinction of fire". Once a scientist has grasped the essence of thunder, she can then also explain what (in general) is required for thunder to occur, viz., fire must be extinguished in the clouds; the resulting noise in the clouds that is produced by the extinction of fire is thunder. ${ }^{10}$

It is not immediately obvious that the metaphysical "why"-questions Aristotle is considering in Met. Z.17 are amenable to the model for scientific inquiry he lays out in the Posterior Analytics. One of Aristotle's concerns in Met. Z.17 is that the metaphysical "why"-questions under discussion might appear trivial, since one might mistakenly take them to be of the form, "Why is something the same thing as itself?". To put this triviality worry to rest, Aristotle argues that the metaphysical "why"-questions at issue, despite appearances, are really of the form, "Why does one thing belong to another (distinct) thing?". If this result can be established, so Aristotle

9 To justify this proposed conception of the relationship between Aristotle's scientific project in the Posterior Analytics and his metaphysical concerns in Met. Z.17 properly would of course require significant work which I cannot hope to accomplish within the confines of the present discussion.

${ }^{10}$ Very briefly, I see definitions, explanations, essences and causes as being related in Aristotle as follows. Definitions figure as first principles or axioms in demonstrations, which, according to the theory of scientific reasoning laid out in the Posterior Analytics, are the proper syllogistic vehicle by means of which scientific explanations can, and perhaps ought to be, conveyed. As I read Aristotle, the explanatory force of definitions is underwritten by the causal power of essences, viz., the worldly (i.e., non-linguistic) correlates of definitions. I investigate these issues in more detail in (Koslicki 2012). We will have further occasion below to consider the sense in which Aristotelian essences do genuine causal work. 
reasons, then the metaphysical "why"-questions at issue would involve the predication of one thing of another (distinct) thing and the triviality worry is thereby avoided, on the assumption that it is never trivial to predicate one thing of another (distinct) thing.

One might wonder whether the scientific "why"-questions with which Aristotle is concerned in the Posterior Analytics, e.g., "Why does thunder occur?", are also supposed to be of the form, "Why does one thing belong to another (distinct) thing?", given the strong connection I see between Aristotle's scientific and his metaphysical projects. Aristotle indicates at 1041a2426 that the point does apply to the scientific case as well: he tells us there that, when we ask such questions as "Why does thunder occur?" or "Why is sound produced in the clouds?", the inquiry in question concerns the predication of one thing of another (distinct) thing. I take it that, by requiring the statements in question to be of the form, "One thing belongs to another (distinct) thing", Aristotle is at least in part stating a minimal predicational requirement that is imposed on statements in order for them to be eligible to occur in a demonstrative syllogism. Such statements must at least be of the form, "One thing belongs to another (distinct) thing" (e.g., "Not twinkling belongs to planets"). In addition, as we know from the Posterior Analytics, statements which are eligible to occur in a demonstrative syllogism must of course satisfy other requirements as well. Since demonstration, for Aristotle, is a species of deduction, any statement which is suitable to occur in a demonstration must also at least be suitable to occur in a deduction. But such statements, as Aristotle develops in the Prior Analytics, must be of the form, $A x B$, where $A$ and $B$ are terms (i.e., with $A$ being the predicate-term and $B$ being the subject-term) denoting universals (i.e., species and genera) and $x$ corresponds to one of the four syllogistic relations that can obtain between terms ('A belongs to all B', 'A belongs to no B', 'A belongs to some B' or 'A does not belong to some B'). In addition, statements that are eligible to occur in a demonstrative syllogism, in Aristotle's view, must also express propositions that are necessarily true. Thus, I take it that, if a statement such as "Being a house belongs to houses" really did assert an identity, it would not be eligible to occur in a demonstrative syllogism, or even, for that matter, in a regular deductive syllogism. Of course, as I go on to discuss, given Aristotle's proposed re-interpretation, there is a way of understanding such statements according to which they do not in fact assert an identity, but are rather of the form, "One thing belongs to another (distinct) thing". These statements are therefore at least in principle eligible to occur in demonstrative syllogisms, provided that they can also be construed in such a way as to satisfy the other requirements Aristotle imposes on such statements. 
In order to show that the metaphysical "why"-questions under consideration in fact conform to the desired pattern, Aristotle proposes that we understand the questions at issue in the following way:

[...] [C]learly the question is why the matter is some individual thing, e.g. why are these materials a house? Because that which was the essence of a house is present. And why is this individual thing, or this body in this state, a man? Therefore what we seek is the cause, i.e. the form, by reason of which the matter is some definite thing; and this is the substance of the thing. (Met. Z $17,1041 b_{4}-9$ )

These reformulations of the "why"-questions at issue present us with a prima facie difficulty. For strictly speaking it does not seem correct to predicate being a house or a human being directly of the matter in question (e.g., bricks and stones or a human body), since the matter at most only composes a house or a human being. In order to avoid this apparent mis-attribution, I propose that we interpret Aristotle's reformulations as follows. The question, "Why does being a certain kind of thing (e.g., a house) belong to the matter at issue (e.g., the bricks and stones)?", should really be understood as asking why the matter in question composes a thing of that kind. Thus, the question at issue is not why a house is composed of bricks and stones (rather than some other matter); instead, the question is why some bricks and stones compose $a$ house (rather than some other kind of thing, e.g., a bridge). So understood, Aristotle urges that the correct answer to these questions is: "Because the essence of the thing is present in the matter composing it". ${ }^{11}$

Given the explanatory role of definitions, a further complication would result from reading Aristotle as directly predicating being a house or a human being of the matter composing the house or human being. For suppose the matter composing a house or a human being is mentioned in the definition which states what it is to be a house or a human being. (I return to the issue of whether, and to what extent, Aristotelian definitions should be read as containing a reference to matter briefly below.) In that case, the assumption that being a house or a human being can be directly predicated of the matter in question, appears to lead to the following circularity: the definiendum (viz., being a house or a human being) now seems to be itself included in the definiens (viz., some suitable matter which itself is a house or a human being and in which the essence in question is present). Given my proposed interpretation, I do not believe that Aristotle in fact succumbs

${ }^{11}$ This, in my view, is also the most sensible interpretation of the puzzling claim, to which Aristotle seems to commit himself in certain places, that form can be predicated of matter (see for example Met. Z.3, 1029a23-24). According to the reading I am proposing above, we should understand this claim as requiring only that the matter in question composes a matter-form compound in which the corresponding form is present. 
to this circularity worry. To see why this is the case, however, we must await my brief sketch below of how I conceive of the role of matter in Aristotelian definitions for the specific case of living organisms.

In addition, the passage just cited also reveals that Aristotle takes the essence, i.e., the cause of each thing's being what it is, to be the form of the thing under consideration. The identification in question takes place in a parenthetical remark at 1041b8 (cf., "but this is the form (touto desti to eidos)"), which most commentators regard as a later insertion. ${ }^{12}$ The occurrence of "eidos" ("form") in this passage also marks the only explicit appearance of this term in all of Met. Z.17. Presumably, it is only once we have arrived at the end of Met. Z.17, the culmination of all of Met. Z, that we are entitled to conclude that the entity in question which best answers to the relevant designations accumulated in this chapter (viz., "the essence", "the primary cause of each thing's being what it is", "nature", "principle", and "the substance of the thing") is indeed the form of a matter-form compound. ${ }^{13}$

To complete Aristotle's response to the triviality objection cited above, it still remains to be established that a thing and its matter are indeed distinct. Aristotle argues in support of this claim by means of a regress-argument which is given at the end of the chapter (see 1041b11-33) and which is meant to apply to a particular class of complex entities, namely wholes which are not "heaps" (sōros) but one (hen), i.e., unified. ${ }^{14,15}$ For the purposes of illustration, Aristotle uses the syllable, "BA", and flesh as examples of unified wholes. We can see from considering these cases, so Aristotle reasons, that a unified whole and its matter are distinct, since it is possible for the syllable,

${ }^{12}$ See for example Frede's and Patzig's (1988) comments on 1041b7-9 and, relatedly, 1041a2728.

${ }^{13}$ We are thus meant to converge on the substantive conclusion at the end of Met. Z.17, as the culmination of all of Met. Z, that form is primary substance (see also Burnyeat 2001). As briefly outlined in Section 2.1, I favor the following construal of the claim that form is primary substance: it is the substance of a matter-form compound more so than the matter (using "substance" here in a relational, comparative and non-taxonomical sense).

${ }^{14}$ Thus, even though we spoke earlier of "things", in an apparently completely unrestricted way, the main claims of Met. Z.17 are really only meant to apply to a restricted class of entities, namely unified wholes. That unified wholes are in fact correctly analyzed as matterform compounds, and in particular that there is more to them besides their matter, I take to be the conclusion to which Aristotle's regress-argument at the end of Met. Z.17 is meant to lead, rather than a premise to which we can simply help ourselves at the outset of the discussion. Since Aristotle here contrasts unified wholes with heaps, we can also infer that the main claims he takes himself to establish in this chapter are not intended to apply to heaps: it is apparently not the case, then, that there is more to a heap besides a plurality of elements.

${ }^{15}$ My exposition here of Aristotle's regress argument in Met. Z.17 will be brief, since I have already commented extensively in other work on what I take Aristotle's reasoning in this passage to be (see in particular Koslicki 2006, 2008). 
"BA", or flesh to be dissolved into its material components, viz., the elements (stoicheia) of which it consists (the letters, "B" and "A"; earth, air, fire and water). In this case, the unified whole in question (the syllable; flesh) is gone, but the elements of which it previously consisted (the letters; earth, air, fire and water) are still there. This possibility, so Aristotle argues, brings out that there must be more to a syllable or flesh besides the material components or elements composing them: a "something else" (heteron $\mathrm{ti}$ ). What could this "something else" be? Aristotle considers three possibilities: either (i) the "something else" is itself an element; or (ii) it is composed of elements; or (iii) it is neither an element nor composed of elements. The first and the second case, Aristotle reasons, lead to a regress. As a result, he embraces the third possibility.

The first case. If the "something else" is itself an element, then we need a new "something else" and hence are launched on a regress. For if the first "something else" is itself an element, then the unified whole (e.g., the syllable, "BA") is composed of the formerly identified elements (the letters, " $\mathrm{B}$ " and "A") plus the new element (the first "something else"). But now, it seems, we arrive in the same situation as before: the unified whole could be dissolved into the elements which compose it, while the elements can persist through this transformation. But then there must be more to the unified whole besides the previously identified elements plus the new element.

The second case. The "something else" is itself composed of elements. ${ }^{16}$ But if the "something else" is itself composed of elements, then we again find ourselves in the same situation as before. For then there must be more to the "something else" besides the elements of which it is composed; and we again need to posit a new "something else", which accounts for the distinction between the unified whole and the elements which compose it.

The third case. The "something else" is neither itself an element nor composed of elements. This is the position Aristotle adopts:

The syllable, then, is something-not only its elements (the vowel and the consonant) but also something else; and the flesh is not only fire and earth or the hot and the cold, but also something else. [...] But it would seem that this is something (ti touto), and not an element (stoicheion), and that it is the cause (aition) which makes this thing flesh and that a syllable. And similarly in all other cases. And this is the substance of each thing (ousia de hekastou men touto); for this is

${ }^{16}$ As I have argued elsewhere (see Koslicki 2006, 2008), I read the second case as involving an application of the so-called Weak Supplementation Principle, according to which a complex entity which has a proper part must have at least another proper part disjoint from the first one. If the "something else" is composed of elements, so Aristotle reasons here, it must be composed of more than one element; otherwise, it is numerically identical to the one element and the second case collapses into the first case. 
the primary cause of its being (touto gar aition prōton tou einai); and since, while some things are not substances, as many as are substances are formed naturally and by nature, their substance would seem to be this nature (phusis), which is not an element but a principle (archē). An element is that into which a thing is divided and which is present in it as matter (hule) $)$ e.g. $a$ and $b$ are the elements of the syllable. (Met. Z.17, 1041b16-33)

Based on this regress-argument, Aristotle takes himself to have established by the end of Met. Z.17 that there is more to a unified whole than its matter. Assuming that the "something else" in question is indeed the form, we therefore reach the conclusion that unified wholes are correctly analyzed as matter-form compounds. This result supports Aristotle's earlier claim that the metaphysical "why"-questions he is investigating in Met. Z.17 indeed conform to the desired pattern, "Why does one thing belong to another (distinct) thing?", since we can now take these questions to be asking of the matter composing a certain thing (e.g., the letters, "B" and " $A$ ") why it composes a thing of that kind (e.g., the syllable, "BA"). The triviality worry raised earlier, in Aristotle's mind, has thereby been successfully defeated. ${ }^{17}$ If we want to know what bears the primary responsibility for some matter composing a certain kind of thing (e.g., a house, a human being, a syllable or flesh), Aristotle's sides with the form, which he takes to be the entity answering to the designations, "principle", "nature", "essence", and "the primary cause of each thing's being what it is". Given his motto for the chapter, "substance is a principle and a cause", it is thus not surprising that the form of a matter-form compound, in Aristotle's view, is more deserving of the title,

${ }^{17}$ Aristotle's regress argument relies on the idea that the matter which comes to compose a matter-form compound can in fact be separated (and not just conceptually) from the matter-form compound itself which the matter in question comes to compose. The question arises, however, as to whether Aristotle's point concerning the separability of the matter from the matter-form compound transfers over from the merely illustrative case of artifacts to the real intended target of his argument, viz., natural things, in particular living organisms. For, in the case of living organisms, Aristotle notoriously faces serious difficulties in trying to isolate something which fulfils the requirements he himself imposes in Met. $\Theta .7$ on what is to count as pre-existing or post-existing matter, i.e., which has what it takes to be potentially, say, a human body without already composing something that is actually a human being (cf., Met. $\Theta .7$, 1049a11-18). Perhaps in some cases, e.g., flesh (one of Aristotle's examples in the regress argument), the matter can be straightforwardly separated (and not just conceptually) from the matter-form compound it comes to compose once the form is present in the matter in question. Nevertheless, to ensure the across-theboard applicability of the regress argument to the case of living organisms, Aristotle may need to reconsider some of his other commitments which lead him to view artifacts and living organisms in such a strongly disanalogous way. 
"substance", than its matter. ${ }^{18}$

As my discussion of the regress argument has brought out, I read Aristotle, in the second half of Met. Z.17, as trying to establish (for the special case of unified wholes, i.e., matter-form compounds) that a thing and its matter are indeed distinct ("the distinctness claim"). Establishing the distinctness claim, in my view, is required of Aristotle if he wishes to complete his response to the triviality worry raised in the first half of Met. Z.17. One might wonder, however, whether the regress argument is not also meant to accomplish other goals, viz., in particular the establishment of what we might call "the unity claim": that the form of a matter-form compound is the principle and cause of its unity. If the second part of Met. Z.17 is in fact intended to accomplish such additional goals, then the further question arises as to how (if at all) the first half of Met. Z.17 contributes to this enterprise. Very briefly, I read Aristotle, in the second half of Met. Z.17 as arguing merely that there must be more to a unified whole besides the matter of which it is composed and that the contrast between unified wholes and mere heaps can be traced to the presence or absence of the extra ingredient he identifies there (viz., form). But we do not find, in the second half of Met. Z.17, any indication of how Aristotle thinks form actually manages to establish unity within a matter-form compound. And while, in other texts, Aristotle certainly attempts to answer this question (see note 21 below), I have my doubts as to whether his strategy of trying to solve the problem of unity for matter-form compounds, as he does, by appeal to the actual-potential distinction is in the end really successful. In connection with our more immediate concerns, however, my reading of the regress argument does have the advantage of releasing us from the obligation of having to explain how (if at all) the earlier parts of Met. Z.17 are meant to contribute to the alleged establishment of the unity claim to which Aristotle evidently commits himself in the second half of Met. Z.17. Insofar as the different sections of the chapter can be viewed as being centered on the establishment of the distinctness claim, the coherence of Met. Z.17 as a whole therefore becomes intelligible and straightforward.

\footnotetext{
${ }^{18}$ This is not to say, however, that the matter of a matter-form compound does not qualify for the title, "substance", at all; only that it does so to a lesser degree than form. As I have briefly indicated, I interpret Aristotle's designation, in Metaphysics $\mathrm{ZH} \Theta$, of form as primary substance (in addition to its being non-taxonomic and relational) as indicating a comparative ranking, according to which form qualifies as substance more so than his other main candidates, viz., matter and the matter-form compound. However, this comparative ranking is consistent with the idea that the other candidates under consideration also qualify for the title, "substance", to some degree, albeit less so than form. I take this to be the view on which Aristotle converges as a result of his investigation into substance in the middle books of the Metaphysics.
} 
But some lingering questions about Met. Z.17 as well as Met. Z. as a whole remain: what justifies Aristotle in assigning such a high level of priority to the form of a matter-form compound, in its role as a principle and cause, over the matter? After all, we know from other texts (e.g., Phys. I-II) that matter, in his view, also functions at least as $a$ principle, $a$ nature and $a$ cause associated with the matter-form compound, viz., its material cause. In Met. Z.7-9, where Aristotle focuses on the diachronic processes of coming to be, he emphasizes that both the matter and the form (along with the agent, where applicable) must be presupposed in an explanation of the diachronic causal processes involved in producing a matter-form compound. Moreover, there are reasons for thinking that, at least in certain cases, the elements composing a thing must also figure in its definition: for example, when we state what it is to be the syllable, "BA", we must presumably mention the letters, "B" and "A", of which the syllable is composed, in addition to the order in which they occur, viz., the fact that "B" precedes "A". This observation suggests that the matter composing a matter-form compound might even be definitionally on a par with its form. ${ }^{19}$ Given these significant explanatory tasks, we begin to wonder whether the matter composing a matter-form compound was not in fact unfairly downgraded by Aristotle in his search for primary substance.

\subsection{Met. $\Theta .8$ : The Priority of the Actual over the Potential ${ }^{20}$}

The key to understanding how the causal priority claim we encounter in Met. Z.17 might be justified further is to appreciate its connection to the following two positions Aristotle endorses elsewhere: (i) that form is related to matter as what is actual is related to what is potential (see DA II.1, Met. H.6) and (ii) that actuality (energeia/entelecheia) in general is prior to potentiality

${ }^{19}$ According to the reading I go on to develop below, the illustrative example involving the syllable will turn out to contrast in significant respects with Aristotle's intended target cases, viz., natural things and, in particular, living organisms. In the case of the syllable, "BA", it is plausible to think that the specific elements of which the syllable is composed, viz., the letters, "A" and "B", must be mentioned in the definition which states what it is to be the syllable in question, along with the order in which these letters must occur when they compose the syllable in question. In contrast, according to the approach I propose below, the matter composing a living organism will not figure in the same specific way in the definition which states what it is to be the kind of living organism in question. But I take this contrast to point us precisely to one of the central reasons for Aristotle's reluctance to classify such things as syllables as full-fledged substances (in the taxonomic absolute sense).

${ }^{20}$ My discussion of Met. $\Theta$ is very much indebted to (Makin 2006), even when the interpretations I adopt diverge from his. 
(dunamis) (see Met. $\Theta .8){ }^{21}$

In Met. $\Theta .8$, Aristotle recognizes three senses of "priority": priority in definition $(\log \bar{o}(i))$; priority in time $($ chronōo $(i))$; and priority in substance (ousia(i)). He intends to establish there that what is actual is prior to what is potential according to all three notions of priority, with one qualification: there is a sense in which potentiality is temporally prior to actuality; but in another sense, actuality is even temporally prior to potentiality. ${ }^{22}$

What is actual, in Aristotle's view, is prior to what is potential according to the first sense of "priority", viz., priority in definition, in that the potential must be defined by reference to the actual, but not vice versa (1049b12-17). Aristotle illustrates this point by appeal to the relation between a capacity and the activity which results from the exercise of this capacity: someone who has the capacity to build a house is potentially building a house, while someone who is exercising the capacity in question is actually building a house. In order to define what it is to have the capacity to build a house (i.e., to be potentially building a house), for Aristotle, we must appeal to the corresponding activity (viz., to be actually building a house) which results from the exercise of the capacity at issue. But the reverse is not the case: an activity (e.g., to be actually building a house) is not defined by appeal to the corresponding capacity (viz., to be potentially building a house).

We may not be completely persuaded, on the basis of this illustration, that what is actual is in fact definitionally prior to what is potential, as Aristotle holds. What would be wrong with defining what it is to engage in a certain activity (e.g., to be actually building a house) by reference to the corresponding capacity (viz., to be potentially building a house)? After all, a builder is actually building a house, or so it seems, precisely when she is exercising the relevant skills involved in her possession of the capacity to build a house. It thus appears as though, as far as definitions are concerned, the

${ }^{21}$ In Met. H.6, Aristotle proposes that the apparent puzzle concerning the unity of the matterform compound is resolved once we realize that the form-matter pair is an instance of the more general actual-potential distinction (1045a20-1045b7). A particular application of this doctrine to the case of living organisms occurs in DA II.1, where Aristotle argues that the soul (i.e., the form of the living organism) is the first actuality of an organized natural body (i.e., the matter of the living organism) that is potentially alive (412a16-b1o). For reasons of space, I cannot, in the present context, comment on the vexing question of how exactly we are to understand Aristotle's proposed solution to the unity problem. I simply take it for granted here that (i) is indeed a position Aristotle wholeheartedly endorses.

${ }^{22}$ For other texts in which Aristotle distinguishes between different senses of "priority", see also Cat. 12, Met. $\Delta .11$ and Met. Z.1. It is an interesting interpretive exercise, in which I unfortunately cannot engage here, to compare the three senses of "priority" we find in Met. $\Theta .8$ with the distinctions Aristotle draws in these other texts. I do, however, briefly comment below on some of the connections I see between the three kinds of priority Aristotle distinguishes in Met. $\Theta .8$ and Met. Z.1, respectively. 
relationship between capacities and the activities which result from the exercise of these capacities is entirely symmetric. I will try to bring out below why Aristotle thinks that, in the case of the matter-form distinction, what is actual (form) is in fact definitionally prior to what is potential (matter).

Secondly, Aristotle argues that what is actual is prior to what is potential in time in a qualified sense (1049b17-1050a3). Consider for example the relation between a child (viz., something that is potentially a fully developed mature human being) and an adult human being (viz., something that is actually a fully developed mature human being). In order for something that is actually a fully developed mature human being to come about, something that is potentially a fully developed mature human being (viz., a child) must precede the adult human being temporally. In this sense, what is potential is temporally prior to what is actual. However, children, as Aristotle remarks, are in turn themselves temporally preceded by adult human beings (viz., their parents), who in addition are causally responsible for their creation. In this second way, what is actual does temporally precede what is potential after all.

Again, we may wonder why the right conclusion to draw from Aristotle's remarks concerning priority in time is not that the temporal relationship between what is actual and what is potential is entirely symmetric. As Aristotle notes, what is potential is temporally prior to what is actual in one sense, though what is actual is also temporally prior to what is potential in another sense. How, then, does the temporal relationship between what is actual and what is potential contribute to Aristotle's overall thesis in Met. $\Theta .8$, that what is actual in general is prior to what is potential? We must assume that Aristotle regards the temporal and causal priority of parents over their children as somehow trumping the mere temporal priority of children over the adult human beings into which they develop. It will come out more clearly below how Aristotle's priority claims in Met. $\Theta .8$, as they pertain to the matter-form relationship, should be construed as having causal force.

Finally, what is actual is said to be prior to what is potential according to the third sense of "priority", viz., priority in substance, in the following way:

But it is also prior in substance; firstly, because the things that are posterior in becoming [i.e., in time] are prior in form and in substance, e.g. man is prior to boy and human being to seed; for the one already has its form, and the other has not. Secondly, because everything that comes to be moves towards a principle, i.e. the end. For that for the sake of which a thing is, is its principle, and the becoming is for the sake of the end; and the actuality is the end, and it is for the sake of this that the potentiality is acquired. For animals do not see in order that they may have sight, but they have sight that they may see. And similarly men have the art of building that they may build, and 
theoretical science that they may theorize; but they do not theorize that they may have theoretical science, except those who are learning by practice; and these do not theorize except in a limited sense, or else they have no need to theorize. Further, matter exists in a potential state, just because it may attain to its form; and when it exists actually, then it is in its form. (Met. $\Theta .8,1050 a 4-16)$

It is easiest to illustrate the sense in which what is actual is said to be prior in substance to what is potential by means of a diachronic case. Consider again the relationship between a child (viz., something that is potentially a mature human being) and an adult human being (viz., something that is actually a mature human being). Even though the child is prior in time to the adult human being into whom he or she develops (if all goes well), nevertheless, so Aristotle maintains, the adult human being is prior in substance to the child. For the adult human being, in Aristotle's view, is that for the sake of which (to hou heneka) the child undergoes these processes of development: it is the goal, purpose or end (telos), the principle (archē) and actuality (energeia), that is driving the child's advancement from one stage of maturation to the next. $^{23}$

So far, my illustrations of Aristotle's general priority thesis in Met. $\Theta .8$ have focused on how this thesis applies to matter-form compounds, viz., living organisms. In the case of the builder, it is one and the same living organism who both possesses the capacity in question (viz., to be potentially building a house) and engages in the corresponding activity (viz., to be actually building a house). Similarly, in the diachronic case, it is a single living organism whom we encounter first in an earlier and less fully developed manifestation, as a child, and subsequently in a later and fully developed manifestation, as an adult. But it is obviously very important to Aristotle's metaphysics as a whole as well as his teleological approach to the natural world that the relationship between matter and form should also conform to the general priority thesis he defends in Met. $\Theta .8$. For one thing, the application of the actual-potential distinction to the matter-form case has already come up in the passage I cited just now to illustrate priority in substance (see 1050a4-16). In addition, Aristotle announces both at the outset

${ }^{23}$ In fact, we can make sense of how a not-yet-existent fully developed adult human being, in Aristotle's view, can drive the processes of development undergone by the child he or she once was without having to resort to mysterious mechanisms, such as backward causation. (For helpful discussion of Aristotle's teleology, see (Johnson 2005).) As will come out more clearly below, it is really the form (viz., the child's soul) that is already present in the child from the time of conception to which Aristotle assigns the primary causal responsibility for the child's maturation into an adult human being. As we know from Phys. II, Aristotle views both the matter and the form as internal principles and causes of change and stability within a natural matter-form compound. 
and at the conclusion of the chapter that he takes actuality in general to be prior to potentiality in all three senses of "priority"; and the form-matter pair is clearly presented to us as one of the most significant instances of the more general actual-potential distinction. ${ }^{24}$ We thus expect form as well to be prior to matter in all three of the senses of "priority" cited in Met. $\Theta .8$. In what sense, then, is it true to say of form that it is prior to matter in definition, time and substance?

In what follows, I propose an explicitly causal reading of Aristotle's general priority thesis in Met. $\Theta .8$, as it pertains to the relation between matter and form. ${ }^{25}$ In particular, I argue below that the priority of form over matter in definition, time and substance is best explained by appeal to the role of form as the formal, efficient and final cause of the matter-form compound, respectively, while the posteriority of matter to form according to all three notions of priority is most plausibly accounted for by the fact that the causal contribution of matter is limited to its role as material cause.

One might wonder whether the causal contribution of matter to the matter-form compound is in fact exhausted by its mereological contribution, i.e., as that which at least partially composes the matter-form compound. Very briefly, it strikes me that Aristotle's causal claim regarding matter (that it acts as the material cause of the matter-form compound) must amount to more than the purely mereological claim (that the matter at least partially composes the matter-form compound). As we know from other texts (e.g., Met. Z.7-9 and Phys. I-II), Aristotle also emphasizes the role of matter both in the substantial and the non-substantial changes undergone by matter-form compounds, as is illustrated (in the non-substantial case) for example by the boiling of the blood in the case of anger and (in the substantial case) by the fact that the pre-existing matter is that from which a newly

\footnotetext{
${ }^{24}$ Aristotle begins his discussion of potentiality and actuality in Met. $\Theta$ by considering the relation between capacities and their exercise in the first half of the book (viz., Met. $\Theta .1-5$ ), since he takes this application of the actual-potential distinction to be the clearest and least problematic. In the second half of the book (viz., Met. @.6-9), Aristotle extends the actualpotential distinction to other cases, in particular the form-matter relation as well as the relation between what is eternal and what is perishable. This list is by no means intended to be exhaustive, however, since other subsidiary applications of the actual-potential distinction also crop up in various places. For example, Aristotle thinks of the infinite and the void as merely potential but not actual. See also (Frede 1994) for further discussion of Aristotle's notion of potentiality as well as his overall strategy in Met. $\Theta$.

${ }^{25}$ As I emphasize here, the causal reading of Aristotle's general priority thesis in Met. $\Theta .8$, which I develop in what follows, is tailored to the specific case of matter and form. I want to leave it open, for the time being, whether or how similar causal considerations could help us understand the Met. $\Theta .8$ priority thesis in its application to other intended instances of Aristotle's actual-potential distinction, e.g., the relation between the eternal and the perishable.
} 
created matter-form compound comes to be by the agency of the efficient cause. Some of the ways in which the role of matter within the matter-form compound, despite its causal and compositional contributions, is nevertheless fairly described as limited will emerge below, though a fuller discussion of these issues goes beyond what I could reasonably hope to accomplish in the present context.

Once the causal interpretation of Aristotle's priority thesis, as it pertains to the matter-form relationship, is in place, we can then also see how the work of Met. $\Theta .8$ is connected to the more specific and explicitly causal priority claim we encounter in Met. Z.17, viz., that form is prior to matter in its role as the principle and primary cause of a matter-form compound's being what it is. For my remarks in what follows can be used to unpack and expand upon the very condensed causal claims that are already contained within Met. Z.17, particularly at 1041a27-32 (cited earlier), where Aristotle ascribes various causal roles to the essence of a thing and hence its form as well, given the apparent identification of essence with form. In particular, Aristotle there identifies the essence of a thing as its final and/or efficient cause, depending on the case. Given the interpretive strategy I recommend, we now have the option of reading these causal remarks in Met. Z.17 as a kind of foreshadowing of what is to follow in Met. $\Theta .8$, where the priority of form over matter is subsumed under the more general three-fold priority of the actual over the potential. Given my proposed causal reading, the definitional, temporal and substantial priority of form over matter, which is supplied by Met. $\Theta .8$ but absent from Met. Z.17, serves to substantiate, and provide the needed motivation for, Aristotle's more specific and explicitly causal priority claim in Met. Z.17.

In Met. Z.1, Aristotle already ascribes three kinds of priority to substance (1028a31-1028b2): (i) priority in definition $(\log \bar{o}(i))$; (ii) priority in knowledge (gnōsei); and (iii) priority in time (chronō(i)). The most obvious differences between the three-fold distinctions we encounter in Met. Z.1 and Met. $\Theta .8$, respectively, are as follows. First, the two texts differ with respect to the relata to which the priority relations at issue are attributed: according to Met. Z.1, substance is said to be prior in three ways, presumably to non-substance; according to Met. $\Theta .8$, the actual is said to be prior to the potential in three ways, with form and matter being a special case of the more general actualpotential distinction. Secondly, the notion of priority in substance is (at least not explicitly) mentioned in the Met. Z.1 passage. Thirdly, the Met. Z.1 passage distinguishes between priority in definition and priority in knowledge, while Met. $\Theta .8$ appears to collapse these two notions into one, viz., priority in definition.

There are numerous reasons, however, why referring back to the Met. Z.1 
passage could not do the work of fleshing out the details of the condensed causal remarks we find in Met. Z.17. For one thing, since the Met. Z.1 passage occurs at the very beginning of Aristotle's investigation into substance in Met. Z, it is at this point still very much an open question which type of entity will be selected as the primary contender for the role of substance. Thus, Aristotle could not, at this stage in the game, expect the reader to follow him, if he were to attribute all three kinds of priority to essence/form right away, since it is of course the task of the following chapters to lay the groundwork required to substantiate this choice, which is then made explicit only in Met. Z.17, at the end of his investigation into substance in Met. Z. Secondly, the causal language which is present in Met. Z.17 is completely lacking from the Met. Z.1 passage. Thirdly, commentators have traditionally found it very difficult to offer a satisfying reading of the three kinds of priority Aristotle ascribes to substance in the Met. Z.1 passage. In particular, Aristotle's reference to temporal priority in Met. Z.1 has proven to be especially challenging in this respect, and has prompted commentators to engage in some rather adventurous speculation (as is documented for example in Frede's and Patzig's (1988) comments on 1028a31-1028b2 and 1028a33-34). An existential reading of priority in time, for example, is surely unavailable, since it would saddle Aristotle with the implausible doctrine, to which he would not want to commit, that substances exist in time before non-substances. ${ }^{26}$ In contrast, given my approach, the proposed connection between Met. Z.17 and Met. $\Theta .8$ opens the door to a relatively conservative reading of what Aristotle might have in mind when he attributes temporal priority to substance in Met. Z.1. For, as I go on to argue in what follows, Aristotle's notion of temporal priority in Met. $\Theta .8$, as it applies to the matter-form relationship, should be read in terms of the role of form as the efficient cause of a matterform compound. This notion of temporal priority, which does not require that the substances can or do exist in time before the non-substances, is then available as an interpretive option for Met. Z.1 as well.

\subsection{The Soul as Formal, Efficient and Final Cause}

The relationship between the soul and the body of a living organism, as it is described in De Anima and elsewhere, provides us with a detailed and instructive example of how Aristotle distributes the causal responsibilities within the compound between the matter and the form. For a living organism to be what it is, so Aristotle tells us (see DA II.4, 415b13), is for it to live a certain kind of life, namely one that is characteristic of the kind of organism

${ }^{26}$ For further discussion of why existential readings of Aristotle's ontological priority claims more generally are unattractive, see (Corkum 2008), (Koslicki 2013), (Peramatzis 2008, 2011). 
at issue. ${ }^{27}$ Whatever is the cause of an organism's living as it characteristically does therefore is also the cause of its being what it is. The majority of this causal work, Aristotle argues, is shouldered by the form of a living organism, viz., its soul, which acts as the formal, final and efficient cause of the living organism (see DA II.4, 415b8-28). The matter of the living organism, in contrast, viz., its body, contributes only by way of its role as the material cause of the living organism.

The soul's role as the formal cause of a living organism serves to bring out the sense in which Aristotle regards form as being prior in definition to matter. For when we inspect Aristotle's method of stating what it is to belong to the broad categories into which he divides living organisms (viz., plants, non-human animals and human beings), we notice that in each case the corresponding definitions make reference to the kind of soul the living organism has. More specifically, when Aristotle defines what it is to be a plant, a non-human animal or a human being, he does so by referring to a certain range of activities, and the corresponding capacities, which he regards as being characteristically associated with the living organism in question. In the case of plants, he appeals to nutrition; ${ }^{28}$ in the case of non-human animals, to perception; $;^{29}$ in the case of human beings, to thought. ${ }^{30}$ To be sure, in

${ }^{27}$ It follows immediately from this correlation between an organism's being what it is and its living a certain characteristic life that there can be no such thing, for example, as a dead human being. For nothing that is dead could have the same essence as a human being, for Aristotle, since the definition which states the essence of, or what it is to be, a human being requires that organisms of this kind live a certain kind of life, viz., one that is characteristically human.

${ }^{28}$ Aristotle conceives of the capacity for nutrition in a sufficiently broad manner to include the capacities for reproduction as well as growth and decrease.

${ }^{29}$ I adopt the reading offered in (Johansen 2012, Chapter 12), according to which an animal's ability to engage in locomotion follows from, but is not included in, the definition which states what it is to be an animal. See also Met. Z.10-11 and the reading of these chapters defended in (Frede and Patzig 1988). At Met. Z.11, 103621ff, we see Aristotle struggling with the question of how the ability of animals to engage in locomotion, and the concomitant requirement to be composed of material parts that are suitable for this purpose, should be reflected in the definitions of animals. Frede and Patzig $(1988,212)$ propose that, while the definitions of animals must bring out the "inner connection" between an animal's soul, the suitability of the bodily organs and the animal's ability to engage in locomotion, the definition itself makes reference only to the animal's form, i.e., its soul.

${ }^{30}$ Aristotle thinks of these capacities, and their corresponding activities, as arranged in a series, in which each successive member presupposes the member preceding it, so that whatever is able to engage in perception also possesses the capacity for nutrition, while whatever is able to engage in thought also possesses both the capacity for nutrition and the capacity for perception (see DA II.3, 414b28-415a12). See also (Frede 2008) on the relation, and difference, between perceiving (aisthanesthai), showing sense or being sensible (phronein) and thinking (noiein). As we know from such passages as Met. A.1 and Posterior Analytics II.19, Aristotle had in mind a kind of cognitive progression which takes as its 
each case (with the possible exception of thought), Aristotle holds that the activity in question requires a material basis as well..$^{31}$ However, insofar as the body enters into these activities, it is relegated to an instrumental role for the purposes of carrying out the tasks involved in the organism's characteristic way of life. ${ }^{32}$ The only requirements that are imposed on the matter of which a living organism is composed is that it must be of a suitable type to perform whatever activities are initiated by, and defined by reference to the form, i.e., the soul of the living organism (see DA II.1, 412a28ff; II.4, 415b1521).

The question of whether or to what extent the matter composing a living organism should be mentioned in its definition, i.e., the statement of its essence, has been discussed extensively in the literature (see for example Lennox 2008, Peramatzis 2011); and I can here only very briefly hint at a complex set of issues, a proper treatment of which would take us too far afield. Aristotle's remarks in Phys. II.8-9 suggest that the matter composing a living organism only makes a very generic appearance in the definition of the living organism, as is also implied by DA II.1, according to which the matter composing a living organism is merely required to be of the right type to carry out the characteristic activities associated with its particular kind of soul. Beyond that, however, what counts as suitable in this connection is determined by a specification of the form or telos of the living organism in question. ${ }^{33}$

starting point the perception of particulars, and leads through memory, learning and experience to the more sophisticated and demanding intellectual abilities required for thought, e.g., the ability to grasp universals, give an account and understand the first principles required for demonstrative knowledge (epistēmē) and the other intellectual virtues.

${ }^{31}$ In the case of thought, Aristotle agonizes, for theological and other reasons, over the question of whether and to what extent the body is involved as well in carrying out the activities relating to the intellect. If, in the case of human beings, thinking requires imagination (phantasia), then this activity as well involves a bodily component at least indirectly, since imagination, in Aristotle's view, presupposes perception, which in turn clearly has a material basis. For present purposes, we need not enter into the difficult interpretive question of whether Aristotle in the end takes the intellect to be separable from the body. If he does, then of course the corresponding definitions would make no reference to matter. Otherwise, the same model applies to thought as to the other activities and capacities which Aristotle clearly recognizes as being realized in matter (viz., nutrition, perception as well as all the other capacities and activities which follow from them, e.g. locomotion, imagination, desire, sleeping, dreaming, etc.).

${ }^{32}$ When Aristotle characterizes the natural body as "organikon" (e.g., at DA II.1, 412b5-6), he is commonly understood as meaning, not that the body itself is an instrument or tool, but rather that it comes equipped with parts which play this role. For further discussion, see for example (Barnes 1999), (Bolton 1978) and (Bos 2003).

${ }^{33}$ The soul's role as the final cause of the living organism will briefly occupy us further below. Other key texts, in this connection, are Met. Z.10-11 (see Frede and Patzig 1988 for a reading 
Given the conception of the matter-form relationship I just outlined, we can now also see how Aristotle can escape the circularity objection raised earlier in connection with his apparent practice, in Met. Z.17, of predicating being a house or a human being directly of the matter in question. I recommended there that such statements are best re-interpreted as requiring only that the matter in question composes a house or a human being. Since the matter composing living organisms makes it into the definition of the living organism only in a very generic way, Aristotle does not succumb to the worry that, say, the definition of human being makes reference to human matter, thereby inadvertently smuggling the definiendum into the definiens. For, according to the approach outlined here, to be a human being is to be a living organism composed of a suitable body in which a human soul is present, where what it is for the matter in question to count as "suitable" for the purpose at hand is determined by reference to the relevant form, viz., the human soul, and its associated capacities and activities.

Next, we can elucidate the sense in which Aristotle regards form as being prior in time to matter by appeal to the soul's role as the efficient cause of the living organism. To illustrate this aspect of the soul's causal contribution to the living organism, it helps to consider first an example from the realm of artifacts. A builder, who in Aristotle's view acts as the efficient cause in the construction of a house, initiates a series of changes which (if successful) lead to the end-result that a house-form comes to be present in some suitable materials (e.g., bricks and stones). In this way, something that is actually a house (viz., the newly created house) is produced by the efficient cause (viz., the builder) from something that is potentially a house (viz., the matter that is suitable to compose a house). Throughout this process, however, the builder is guided by a house-form which is already present in her mind to begin with and which is like the house-form that comes to be present in the bricks and stones as a result of the changes implemented by the builder. In a successful case of efficient causation involving the production of an artifact, form is thus prior in time to matter in this sense: before the newly created matter-form compound can be produced, the efficient cause must already be in possession of a form that is of the same kind as the form which comes to be present in the matter as a result of the changes initiated by the efficient cause.

Aristotle conceives of the soul as the efficient cause of the living organism in an analogous manner. To illustrate, consider a case in which a living organism grows by adding more flesh to its body as a result of ingesting and

of these chapters that is congenial to my approach). I discuss the connections between essence/form and matter, which I take to be governed by hypothetical necessity, further in (Koslicki 1997, 2012). 
digesting food. The role played by the soul in this case, in Aristotle's view, is comparable to that played by the builder in the construction of a house. As the efficient cause, the soul initiates a series of changes both in the living organism and in the food that is ingested and digested; these changes, if successful, lead to the outcome that something that is actually flesh (viz., the flesh that is added to the living organism's body) comes to be from something that is potentially flesh (viz., the food that is ingested and digested) by the agency of the soul. In the process, the soul makes it the case that a flesh-form which is like the flesh-form that is already present in the living organism to begin with comes to be present in the properly transformed matter (viz., the concocted food). In this way, a successful case of efficient causation, in this case as well, presupposes a form that is prior in time to the matter underlying whatever changes are involved in a living organism's exercise of its capacity for nutrition. ${ }^{34}$

Lastly, in order to articulate Aristotle's reasons for classifying form as prior in substance to matter, we turn to the role of the soul as the final cause of the living organism. In this connection, it is useful to bear in mind the role of the human soul in Aristotle's specification of the good life for humans, as it is set out in his ethical treatises. As is well-known, Aristotle argues in the context of his so-called "function argument" (NE I.7) that the telos or good for human beings resides in living a certain kind of life, viz., one in which the characteristic activity or function (ergon) for human beings is carried out well. In response to the question of what the function or characteristic activity for human beings might be, Aristotle reasons that it cannot consist in the exercise of a capacity that is exhibited by other living organisms as well, viz., nutrition (which is common to all living organisms) or perception (which is found in non-human animals as well). Rather, he proposes that the good life for humans must involve the exercise of a capacity that is unique to humans, viz., the capacity for thinking. ${ }^{35}$ Aristotle's specification of the

${ }^{34}$ I have illustrated the soul's role as the efficient cause of the living organism here by means of a particular case, viz., an exercise of the living organism's capacity for nutrition. When we attempt to work out how the soul is supposed to act as the efficient cause in other cases, e.g., perception and thought, the details become quite tricky (see (Johansen 2012, Chapter 7) for useful discussion). Nevertheless, Aristotle's claim that the soul is the efficient cause of the living organism is meant to be completely general.

${ }^{35}$ I regret that I can only provide a few brief gestures here in the direction of some of the most important and difficult material in the Aristotelian corpus. A detailed examination of Aristotle's function argument in NE I.7 can be found for example in (Barney 2008). For the role of thinking, as a characteristic activity which distinguishes human beings from other living organisms, see (Frede 2008). Relevant also in this context is Aristotle's conception of the divine intellect in Met. $\Lambda$ as well as his discussion of the active intellect in DA III. Such texts as Met. A.1-2, as well as the emphasis on theoretical contemplation in NE X.710, suggest that human beings, for Aristotle, are at their best when the activities on which 
good life for humans thus proceeds directly by way of the human soul and its associated capacities and activities. In this way, the human soul sets the telos for human beings and acts as their final cause. The human body, in contrast, in its instrumental role, carries out whatever tasks are involved in living a characteristically human life. By the criteria set out in Met. $\Theta .8$, the human soul is therefore prior in substance to the human body; and, more generally, the form of a living organism is prior in substance to its matter.

According to the argumentative strategy I have taken in this paper, Aristotle's causal claims (viz., that the form of a matter-form compound acts as its formal, efficient and final cause) are supposed to lend support to his priority thesis (viz., that the form of a matter-form compound is prior to its matter in definition, time and substance). One might be concerned, however, that the causal claims and the priority thesis are somewhat mismatched in terms of their respective relata: for the causal claims are apparently formulated in such a way that they relate the soul (i.e., the form) to the living organism (i.e., the matter-form compound), while the priority thesis is intended to apply to the relation between the soul (i.e., the form or what is actual) and the body (i.e., the matter or what is potential). Thus, even if we are convinced that the form is in fact causally prior to the matter-form compound, why does this causal priority translate into the causal priority of the form of a matter-form compound over its matter?

Several possible avenues, which I can only briefly outline here, are available in response to this apparent objection to my argumentative strategy. First, the causal claims Aristotle advances in De Anima are in fact often formulated as relating the soul and the body (rather than the living organism), and I have sometimes substituted the living organism for the body, as the second relatum of these causal claims, when I have found it difficult to make sense of these causal claims in their original formulations. Secondly, Aristotle slides back and forth freely between the soul/body formulation and the soul/living organism formulation of these causal claims. For example, at $D A$ II.4, 415b8-12, Aristotle states that the soul is the cause (aitia) and principle (arche) of the living body according to three senses of "cause" and "principle" (viz., as what initiates change, as the end, and as the essence); but he then goes on to illustrate the three-fold causal role attributed to the soul by appealing to claims that are true of the whole living organism as well, and not only, or not even primarily, of its body. Finally, although I suspect that Aristotle would accept both formulations of the causal claims as well as the priority claims, whether these claims take as their relata the soul and the body, or the soul and the living organism, we have in any case already enof the divine intellect, see for example (Burnyeat 2008). 
countered reasons (in Section 2.1) for taking the matter-form compound, for the purposes of the inquiry into substance in the middle books of Aristotle's Metaphysics, to be explanatorily posterior to its principles and causes, viz., matter and form. ${ }^{36}$

\section{Conclusion}

My main target in this paper was Aristotle's causal priority claim in Met. Z.17, according to which the form of a matter-form compound, rather than its matter, bears the primary responsibility, in its role as a principle and cause, for the compound's being what it is. This priority assignment is at least at first sight puzzling, since Aristotle also allocates various causal duties to the matter-form compound itself as well as its matter. Given the centrality of Aristotle's causal priority claim in his search for primary substance in the middle books of the Metaphysics, it is important to understand what motivates him in designating form as the primary cause and principle of a compound's being what it is.

According to the reading I have advanced in this paper, Aristotle's causal priority claim in Met. Z.17 is best evaluated by embedding it within the broader context of Met. $\Theta .8$, where Aristotle argues that actuality (energeia/ entelecheia) in general is prior to potentiality (dunamis) in three ways, viz., in definition, time and substance. I argued that, when applied to the particular case of the matter-form relationship, the priority of the actual over the potential should be read as having causal force. Thus, the priority of form over matter in definition, time and substance is best explained by the role of form as the formal, efficient and final cause of the matter-form compound, respectively, while the posteriority of matter to form according to all three notions of priority is most plausibly accounted for by the fact that the causal contribution of matter is limited to its role as the material cause of the matter-form compound. When approached from this angle, the work of Met. $\Theta .8$ helps to substantiate, and provide the needed motivation for, the more specific and explicitly causal priority claim Aristotle advances in Met. Z.17: that form is prior to matter in its role as the principle and primary cause of a matter-form compound's being what it is.

For the specific case of living organisms, Aristotle's priority claim is borne out by the fact that he ascribes the majority of the causal work that is to be accomplished within the matter-form compound to the soul (its form), whereas the body (its matter) is relegated to a subsidiary and instrumental role relative to the characteristic activities that are initiated by, and defined in

\footnotetext{
${ }^{36}$ Thanks to Umer Shaikh for pressing me on this point which certainly deserves a fuller treatment than I am able to provide in the present context.
} 
terms of, the living organism's soul. As the formal, efficient and final cause of the living organism, the soul, in Aristotle's view, bears the primary causal responsibility for an organism's living in a certain characteristic way and therefore also for its being what it is (given that, for Aristotle, a living organism's being what it is coincides with its living as it characteristically does). The soul therefore, more so than the body or the living organism itself, fits Aristotle's motto in Met. Z.17, viz., "substance is a principle (archē) and a cause (aitia)". If Aristotle's reasoning is meant to extend beyond the case of living organisms, analogous considerations could then be used to justify the causal priority of form over matter and the compound more generally.

\section{Acknowledgements}

I am grateful to the editors of this special issue, Tuomas Tahko and Riin Sirkel, for the excellent idea they had, and the effort they expended, in assembling this volume. Versions of this paper were presented at the 2014 MAWM (Midwest Annual Workshop in Metaphysics) at Indiana University as well as at McMaster University; I have benefitted greatly from the interesting and useful input I received from those who were present at these talks. In addition, my thoughts on Aristotle's conception of substance were very much shaped by a seminar I taught on Metaphysics $\mathrm{ZH} \Theta$ at the University of Colorado-Boulder during the Fall of 2013. I would like to acknowledge the insightful contributions of those who participated in this seminar, in particular Philip Choi, Daniel Coren, Erlantz Etxeberria, Jay Geyer, Mitzi Lee, Bob Pasnau, Caleb Pickard, Chaz Vollmer, Joe Wilson and Alex Wolf-Root. Most of all, however, my thanks go to Wolfgang Mann, Michail Peramatzis and Riin Sirkel, who took the time to provide me with extremely careful, extensive and thought-provoking feedback on an earlier version of this paper. And while I have done my best, given the time and space constraints under which I was operating, to take the concerns raised in their comments into consideration in revising the paper, some of the issues which were brought to my attention are simply too large or complex (or not yet sufficiently well worked out in my own mind) to address them properly within the confines of this paper. I welcome the opportunity, however, to grapple with these questions further in future work, in my continued attempts to develop a clearer understanding of how best to conceive of Aristotle's distinction between matter and form. 


\section{Bibliography}

Barnes, J. (1999). Review of S. Everson, Aristotle on Perception, Classical Review 49: 120-122.

Barnes, J. (ed.) (1984). The Complete Works of Aristotle: The Revised Oxford Translation, Princeton University Press.

Barney, R. (2008). Aristotle's argument for a human function, Oxford Studies in Ancient Philosophy 34: 293-322.

Bolton, R. (1978). Aristotle's definitions of the soul: De Anima II, 1-3, Phronesis 23: 258-278.

Bos, A. P. (2003). The Soul and Its Instrumental Body: A Reinterpretation of Aristotle's Philosophy of Living Nature, Brill, Leiden.

Bostock, D. (ed.) (1994). Aristotle, Metaphysics, Books $Z$ and H, Clarendon Press, Oxford.

Burnyeat, M. (1979). Notes on Book Zeta of Aristotle's Metaphysics, Study Aids Monograph No.1.

Burnyeat, M. (2001). A Map of Metaphysics Zeta, Mathesis Publications, Pittsburgh.

Burnyeat, M. (2008). Aristotle's Divine Intellect, Marquette University Press, Milwaukee.

Corkum, P. (2008). Aristotle on ontological dependence, Phronesis 53: 6592.

Fine, G. (1987). Forms as causes: Plato and Aristotle, in A. Graeser (ed.), Mathematics and Metaphysics in Aristotle, Verlag Paul Haupt, Bern, pp. 69-112.

Frede, M. (1994). Aristotle's notion of potentiality in Metaphysics $\theta$, in T. Scaltsas, D. Charles and M. L. Gill (eds), Unity, Identity and Explanation in Aristotle's Metaphysics, Clarendon Press, Oxford, pp. 173-193.

Frede, M. (2008). Aristotle on thinking, Rhizai 2: 287-301.

Frede, M. and Patzig, G. (eds) (1988). Aristoteles Metaphysik Z, Verlag C.H. Beck, Munich.

Johansen, T. K. (2012). The Powers of Aristotle's Soul, Oxford University Press, Oxford.

Johnson, M. R. (2005). Aristotle on Teleology, Oxford University Press, New York.

Koslicki, K. (1997). Four eighths hephaistos: Artifacts and living things in Aristotle, History of Philosophy Quarterly 14: 77-98. 
Koslicki, K. (2006). Aristotle's mereology and the status of form, Journal of Philosophy CIII: 715-736.

Koslicki, K. (2008). The Structure of Objects, Oxford University Press, Oxford.

Koslicki, K. (2012). Essence, necessity and explanation, in T. Tahko (ed.), Contemporary Aristotelian Metaphysics, Cambridge University Press, Cambridge, pp. 187-206.

Koslicki, K. (2013). Ontological dependence: An opinionated survey, in B. Schnieder, M. Hoeltje and A. Steinberg (eds), Varieties of Dependence (Basic Philosophical Concepts), Philosophia Verlag, München, pp. 31-64.

Koslicki, K. (2014). In defense of substance, Grazer Philosophische Studien. forthcoming.

Lennox, J. G. (2008). 'As if we were investigating snubness': Aristotle on the prospects for a single science of nature, Oxford Studies in Ancient Philosophy 35: 149-186.

Makin, S. (ed.) (2006). Aristotle, Metaphysics, Book $\Theta$, Clarendon Press, Oxford.

Peramatzis, M. (2008). Aristotle's notion of priority in nature and substance, Oxford Studies in Ancient Philosophy 35: 187-247.

Peramatzis, M. (2011). Priority in Aristotle's Metaphysics, Oxford University Press, New York.

Ross, W. D. (ed.) (1924). Aristotle, Metaphysics: A Revised Text with Introduction and Commentary, Clarendon Press, Oxford. 